\title{
The influence of vegetation dynamics on anthropogenic climate change
}

\author{
U. Port ${ }^{1}$, V. Brovkin ${ }^{1}$, and M. Claussen ${ }^{1,2}$ \\ ${ }^{1}$ Max-Planck Institute for Meteorology in Hamburg, Germany \\ ${ }^{2}$ Meteorological Institute, KlimaCampus, University of Hamburg, Germany
}

Correspondence to: U. Port (ulrike.port@zmaw.de)

Received: 15 June 2012 - Published in Earth Syst. Dynam. Discuss.: 5 July 2012

Revised: 22 October 2012 - Accepted: 12 November 2012 - Published: 27 November 2012

\begin{abstract}
In this study, vegetation-climate and vegetationcarbon cycle interactions during anthropogenic climate change are assessed by using the Earth System Model of the Max Planck Institute for Meteorology (MPI ESM) that includes vegetation dynamics and an interactive carbon cycle. We assume anthropogenic $\mathrm{CO}_{2}$ emissions according to the RCP 8.5 scenario in the time period from 1850 to 2120 . For the time after 2120 , we assume zero emissions to evaluate the response of the stabilising Earth System by 2300 .

Our results suggest that vegetation dynamics have a considerable influence on the changing global and regional climate. In the simulations, global mean tree cover extends by 2300 due to increased atmospheric $\mathrm{CO}_{2}$ concentration and global warming. Thus, land carbon uptake is higher and atmospheric $\mathrm{CO}_{2}$ concentration is lower by about $40 \mathrm{ppm}$ when considering dynamic vegetation compared to the static pre-industrial vegetation cover. The reduced atmospheric $\mathrm{CO}_{2}$ concentration is equivalent to a lower global mean temperature. Moreover, biogeophysical effects of vegetation cover shifts influence the climate on a regional scale. Expanded tree cover in the northern high latitudes results in a reduced albedo and additional warming. In the Amazon region, declined tree cover causes a regional warming due to reduced evapotranspiration. As a net effect, vegetation dynamics have a slight attenuating effect on global climate change as the global climate cools by $0.22 \mathrm{~K}$ due to natural vegetation cover shifts in 2300 .
\end{abstract}

\section{Introduction}

Atmospheric $\mathrm{CO}_{2}$ concentrations and climate changes projected for the 21st century (Meehl et al., 2007) are unprecedented in the geological history of the last several million years. Since the geographical distribution of natural plants is controlled by climate, to a large extent (Woodward and Beerling, 1997), spatial distribution of vegetation types will be modified in response to climatic changes. In addition, elevated atmospheric $\mathrm{CO}_{2}$ concentration acts as a fertiliser for the biosphere. Plant productivity and water-use efficiency become higher under increasing atmospheric $\mathrm{CO}_{2}$ conditions until saturation is reached (de Boera et al., 2011). This fertilisation effect leads to extended plant growth and alters the competition among plants.

The response of the terrestrial biosphere to anthropogenic climate change has already been detected in satellite and phenological data. Myneni et al. (1997), Menzel and Fabian (1999), and Zhou et al. (2001) observe increased plant growth in the northern high and mid latitudes $\left(45^{\circ} \mathrm{N}\right.$ to $70^{\circ} \mathrm{N}$ ) from the 1980 s to the 1990 s due to extended growing seasons. Piao et al. (2011) and Beck and Goetz (2011) analyse satellite data for the period from 1986 until 2006 and find increasing plant growth in the tundra region over the whole period. However, a decreasing trend in plant growth occurs in the boreal region from 1996 until 2006.

As the biosphere influences energy, water, and gas fluxes, shifts in plant distribution will in turn lead to changes in regional and global climate. There are two different effects by which the vegetation affects climate can be distinguished, the biogeophysical and the biogeochemical effect. The biogeophysical effect refers to the impact of vegetation on the 
energy, the moisture, and the momentum fluxes due to its physical properties such as leaf area, albedo, and roughness length (Claussen et al., 2001). The biogeochemical effect represents the impact of the biosphere on the chemical composition of the atmosphere. In this study, we refer to the biogeochemical effect only as the influence on the atmospheric $\mathrm{CO}_{2}$ concentration. The biosphere affects land carbon uptake and the atmospheric $\mathrm{CO}_{2}$ concentration since it builds up biomass.

In recent years, climate models coupled to land surface models have become a common tool to assess the influence of the biosphere on the climate. Two different main effects of forests on the climate have been found depending on the region. In the tropics, forests lead to a reduced albedo and an enhanced evapotranspiration compared to bare soil. The albedo reduction is equivalent to a warming, while increased evapotranspiration leads to a cooling. In sum, the cooling outweighs the warming, and forests cool the tropical climate (Snyder et al., 2004).

Unlike tropical forests, boreal forests are suggested to warm climate, since they cover the snow and thus reduce surface albedo strongly compared to herbaceous vegetation and low-stand shrubs (Brovkin, 2002; Matthews et al., 2004; Essery et al., 2009). The impact of temperate forests on climate depends on the seasons. In winter and spring, temperate forests warm the regional climate by reducing the albedo, while in summer they cool the climate by increasing the latent heat flux. On a global scale, the biogeophysical effect of forests is likely to lead to a warmer climate. The cooling effect of enhanced transpiration in the tropics is weaker than the warming effect of reduced land surface albedo in the high latitudes (Brovkin et al., 2009).

Taking the biogeochemical effect into account modifies the net impact of forest on climate. In idealised deforestation/afforestation experiments, model simulations show that tropical forests cause a cooler climate, since they take up large amounts of carbon. The resulting cooling further enhances the cooling due to increased evapotranspiration (Claussen et al., 2001; Bala et al., 2007; Bathiany et al., 2010). For forests in the high and mid latitudes, the biogeochemical and the biogeophysical effects counteract. Biomass build up by forest tends to cool climate, while the albedo reduction due to forest leads to a warmer climate. In balance, the albedo effect is stronger and high and mid latitude forests warm regional climate.

Because of the interactions between the terrestrial biosphere and the atmosphere, changes in distribution of vegetation cover (vegetation dynamics) need to be considered when simulating anthropogenic climate change. Based on simulations made with Global Dynamic Vegetation Model coupled to Atmospheric General Circulation Models, the shifts in vegetation cover due to an increased atmospheric $\mathrm{CO}_{2}$ concentration and the resulting influence on the climate (Notaro et al., 2007; O'ishi and Abe-Ouchi, 2009; Yurova and Volodin, 2011) and on the carbon cycle (Jones et al., 2010)
Table 1. Plant Functional Types defined in JSBACH.

\begin{tabular}{ll}
\hline $\begin{array}{l}\text { Vegetation } \\
\text { cover type }\end{array}$ & $\begin{array}{l}\text { Plant } \\
\text { Functional Type }\end{array}$ \\
\hline \multirow{2}{*}{ trees } & $\begin{array}{l}\text { tropical evergreen trees } \\
\text { tropical deciduous trees } \\
\text { extra-tropical evergreen trees } \\
\text { extra-tropical deciduous trees }\end{array}$ \\
\hline \multirow{2}{*}{ shrubs } & $\begin{array}{l}\text { rain green shrubs } \\
\text { cold shrubs }\end{array}$ \\
\hline \multirow{2}{*}{ grass } & $\mathrm{C}_{3}$ grass \\
& $\mathrm{C}_{4}$ grass \\
\hline
\end{tabular}

have been assessed. Notaro et al. (2007) assume four times pre-industrial atmospheric $\mathrm{CO}_{2}$ concentrations and find that increased temperatures in the northern high latitudes lead to a northward expansion of boreal forests. The extended tree cover leads to further warming since the surface albedo is reduced. For the response of the Amazonian forest, simulation results differ. Cox et al. (2004), Betts et al. (2004), and Notaro et al. (2007) find a decreasing tree cover since the regional climate becomes too dry. The resultant reduction in evapotranspiration leads to a further drying. However, Yurova and Volodin (2011) simulate no forest degradation in the Amazon region, as soil moisture remains sufficient to maintain forest growth.

In our study, we assess the changes in the biosphere due to anthropogenic $\mathrm{CO}_{2}$ emissions and the resulting climate change based on model simulation performed with the MPI ESM, including a dynamic vegetation module and an interactive carbon cycle. As we focus on natural land cover changes, we only include natural vegetation dynamics and neglect anthropogenic land use change. The biogeophysical and the biogeochemical effect are separated in order to compare the strength of them. We assume a transient $\mathrm{CO}_{2}$ emission scenario according to the Representative Concentration Pathway 8.5 (RCP 8.5) until the year 2120 and set the $\mathrm{CO}_{2}$ emissions to zero afterwards. The simulations continue until 2300. This is the first study where the response of the biosphere to anthropogenic climate change and the resulting impact on climate due to the $\mathrm{CO}_{2}$ emissions included in the RCP 8.5 scenario are assessed. By extending the simulation until the year 2300, we obtain the long-term effect of vegetation dynamics on a time scale over several centuries, which is unique.

The results are presented and discussed in three steps. First, the simulated climate changes and the subsequent shifts in vegetation cover until 2120 are examined, followed by the anthropogenic climate changes as well as the biogeographical shifts by the year 2300. In the third step, the impact of vegetation dynamics on the regional and the global climate as well as on the carbon cycle are analysed. Thereby, the biogeophysical and the biogeochemical effect are examined separately. 

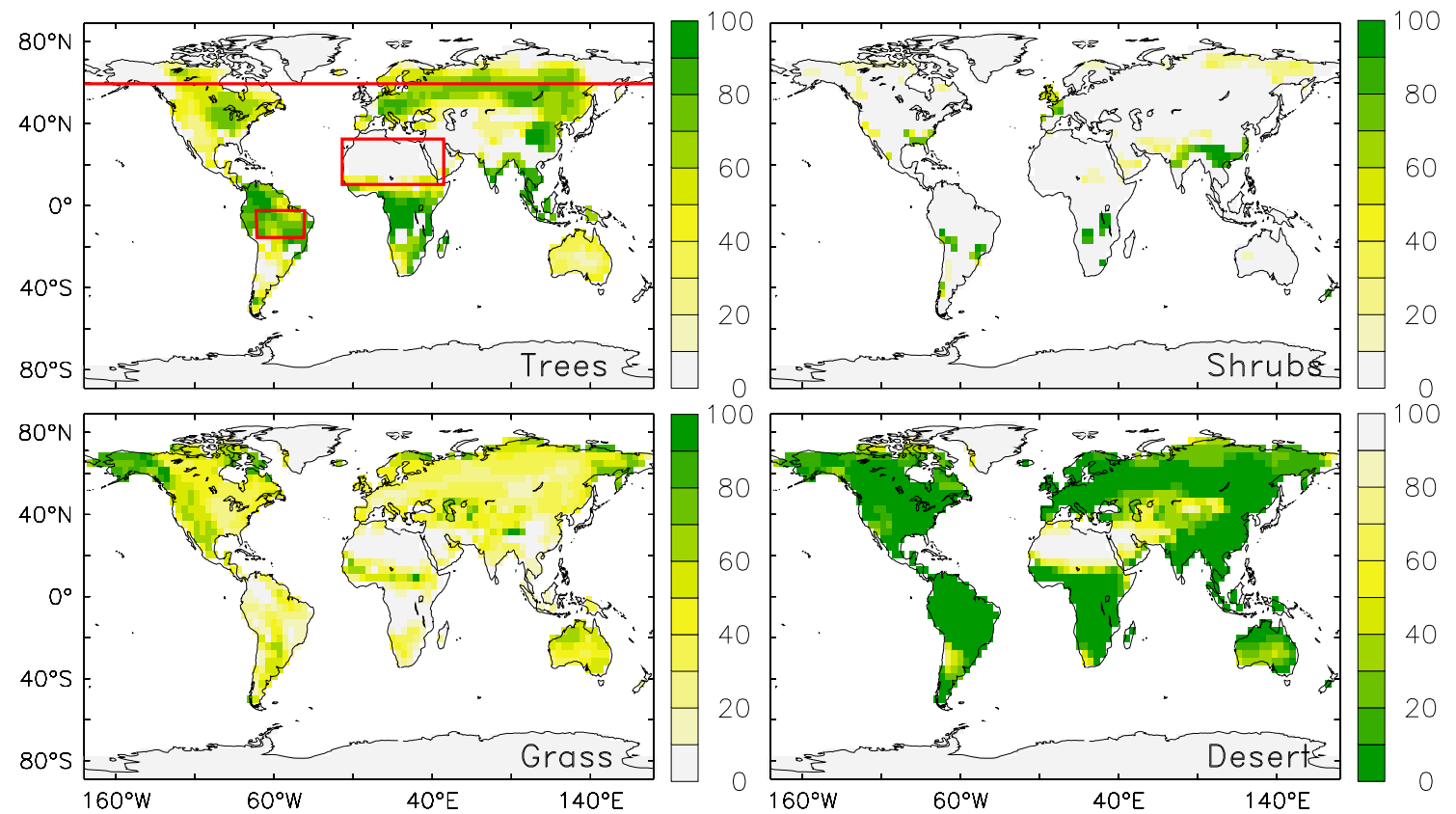

Fig. 1. Equilibrium vegetation distribution in the CTL simulation in [\%], averaged over $50 \mathrm{yr}$. Trees include tropical evergreen and deciduous forest as well as extra-tropical evergreen and deciduous forest. Grass comprises $\mathrm{C}_{3}$ grass and $\mathrm{C}_{4}$ grass, while shrubs include rain green and cold shrubs. Bare areas are interpreted as desert. The marked regions are chosen for detailed analyses of vegetation and climate changes.

\section{Model setup and methods}

The Earth System Model of the Max Planck Institute for Meteorology (MPI ESM) employed here consists of the Atmospheric General Circulation Model ECHAM5 (Roeckner et al., 2003), the Jena Scheme for Biosphere Atmosphere Coupling in Hamburg (JSBACH) (Raddatz et al., 2007), the Max Planck Institute Ocean Model (MPI-OM) (Jungclaus et al., 2006), and the ocean biogeochemistry model HAMOCC5 (Wetzel et al., 2005). All components are connected with each other in an interactive carbon cycle. ECHAM5 runs in a T31 resolution (approx. $3.75^{\circ}$ ) with 19 levels in the vertical. The grid of the ocean model has a resolution of about $3^{\circ}$ and 40 levels. JSBACH includes a dynamic vegetation module based on a tiling approach (Brovkin et al., 2009). The vegetation is represented by the eight Plant Functional Types (PFTs) listed in Table 1. For the analysing process, these PFTs are further grouped into forest, shrubs, and grass.

Four simulations were performed as listed in Table 2. The control simulation (CTL) runs without anthropogenic $\mathrm{CO}_{2}$ emissions. The atmospheric $\mathrm{CO}_{2}$ concentration varies around $275 \mathrm{ppm}$ and the climate is in equilibrium. The equilibrium vegetation distribution is depicted in Fig. 1. The simulated tree cover distribution matches observations based on satellite data in the main boreal and temperate pattern (Brovkin et al., 2009).

The STAT simulation is forced by $\mathrm{CO}_{2}$ emissions according to the anthropogenic $\mathrm{CO}_{2}$ emissions included in the Rep- resentative Concentration Pathway 8.5 scenario (RCP 8.5). The emissions last until 2120 and accumulate to $3000 \mathrm{Pg}$ Carbon by 2120 . Afterwards, the simulation continues without $\mathrm{CO}_{2}$ emissions until 2300. The vegetation cover is held constant at the equilibrium distribution of the control simulation. However, the plant productivity, Leaf Area Index (LAI), and canopy conductance respond to the increased atmospheric $\mathrm{CO}_{2}$ concentrations. Differences in the climate between the STAT and the CTL simulation reflect the climate change due to the $\mathrm{CO}_{2}$ emissions and plant physiological changes.

The third simulation, referred to as DYN simulation, is driven by the same $\mathrm{CO}_{2}$ emissions as the STAT simulation $\left(\mathrm{CO}_{2}\right.$ emission according to the RCP 8.5 scenario until 2120 and zero emissions afterwards until 2300). The vegetation cover changes dynamically due to increased atmospheric $\mathrm{CO}_{2}$ concentrations and climate change. Vegetation cover shifts due to land use are not included, i.e. the biosphere only changes naturally. Regarding climate, differences between the DYN and the STAT simulation can be attributed to biogeographical shifts and differences in plant productivity, LAI, and canopy conductance.

In the STAT_PS simulation, the atmospheric $\mathrm{CO}_{2}$ concentration is set to the values calculated in the DYN simulation. The vegetation distribution is fixed to the equilibrium of the CTL simulation. When comparing the DYN and the STAT_PS simulation, climate changes are caused by the different physiological response of the plants and the biogeophysical effect of vegetation cover changes. The 
Table 2. Experimental setup. The used $\mathrm{CO}_{2}$ emission scenario is based on the RCP 8.5.

\begin{tabular}{lrll}
\hline Simulation & Period & Vegetation & $\mathrm{CO}_{2}$ forcing \\
\hline CTL & $1700-2300$ & dynamic & no anthropogenic $\mathrm{CO}_{2}$ emissions \\
STAT & $1850-2300$ & static & $\mathrm{CO}_{2}$ emissions according to RCP 8.5 \\
DYN & $1850-2300$ & dynamic & $\mathrm{CO}_{2}$ emissions according to RCP 8.5 \\
STAT_PS & $1850-2300$ & static & atm. $\mathrm{CO}_{2}$ content as simulated in DYN \\
\hline
\end{tabular}

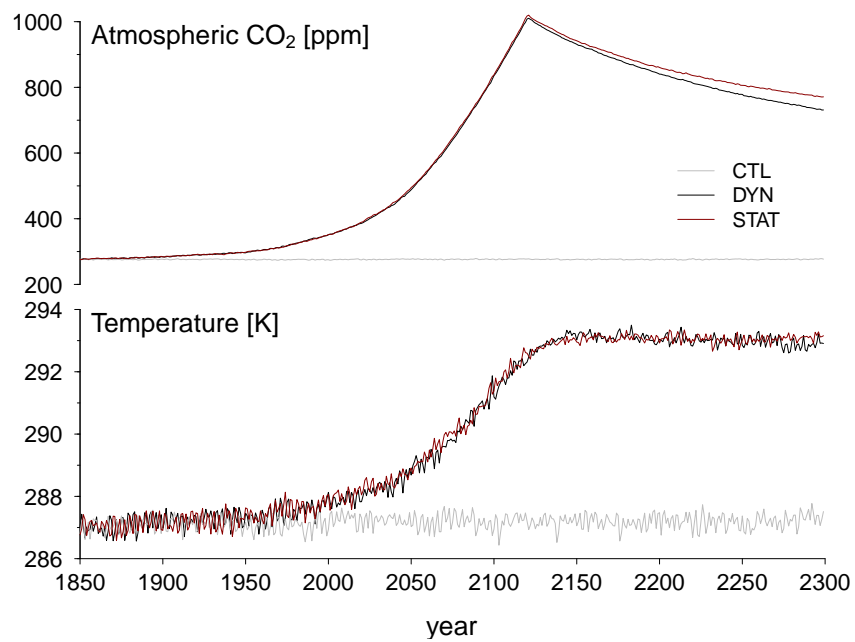

Fig. 2. Time series of annual mean atmospheric $\mathrm{CO}_{2}$ concentration and global annual mean temperature in the CTL (grey line), the DYN (black line), and the STAT (red line) simulation.

plant physiology (plant productivity, LAI, and canopy conductance) changes due to increased atmospheric $\mathrm{CO}_{2}$ concentrations and changing climate. As the atmospheric $\mathrm{CO}_{2}$ concentrations in the DYN and in the STAT_PS simulation are the same and the differences in climate are small compared to anthropogenic climate change, we neglect the physiological differences between the DYN and the STAT_PS simulation. We attribute differences in climate between the DYN and STAT_PS simulation to the biogeophysical effect of vegetation cover shifts.

The changes in the biosphere can be subdivided into two periods. The first period lasts from the year 1850 until 2120, when atmospheric $\mathrm{CO}_{2}$ concentration increases and climate changes rapidly. During this time, $\mathrm{CO}_{2}$ fertilisation and climate change act on the biosphere simultaneously. The second period starts in 2120, when the $\mathrm{CO}_{2}$ emissions are switched off. From 2120 until 2300, the atmospheric $\mathrm{CO}_{2}$ concentration declines, $\mathrm{CO}_{2}$ fertilisation weakens, and climate tends to stabilise. Climate change and subsequent changes in the terrestrial biosphere are presented for these two periods.

The impact of vegetation cover changes on climate and on the carbon cycle are analysed in detail averaged over the last $30 \mathrm{yr}$ of the simulations (2270-2300) since from 2260 the vegetation cover tends to stabilise. Analysis focuses on the

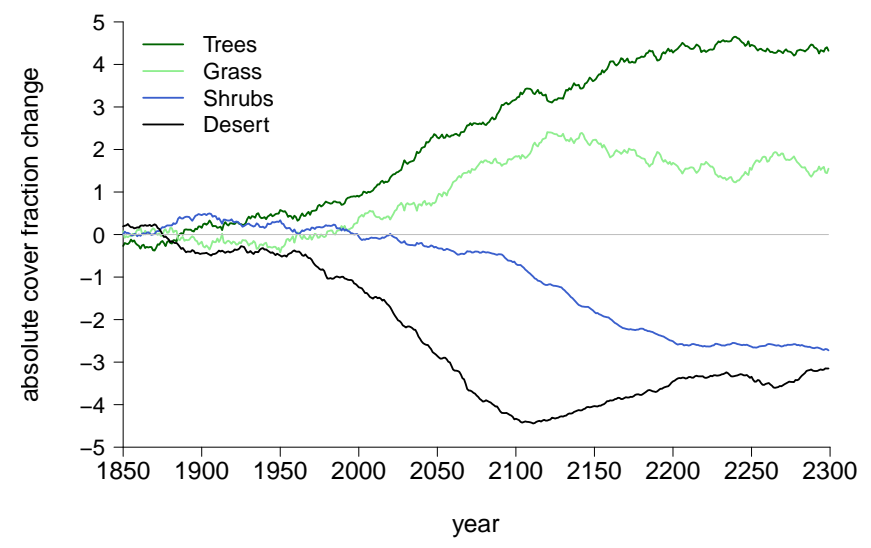

Fig. 3. Time series of changes in absolute global mean vegetation cover (DYN - CTL) in [\%]. Forest includes tropical evergreen and deciduous trees as well as extra-tropical evergreen and deciduous trees. Shrubs contain cold and rain green shrubs and grass includes $\mathrm{C}_{3}$ and $\mathrm{C}_{4}$ grass.

global and on the regional effect of vegetation cover changes on the climate and the carbon cycle. The regions chosen for detailed analysis are the northern high latitudes, the Amazon region, and the Sahara as marked in Fig. 1.

\section{Results and discussion}

\subsection{Changes in climate and vegetation cover during the emission period (1850-2120)}

The extension of the RCP 8.5 scenario used here implies that $3000 \mathrm{PgC}$ are emitted until the year 2120. In response to these $\mathrm{CO}_{2}$ emissions, the atmospheric $\mathrm{CO}_{2}$ concentration in the DYN simulation is larger by $592.1 \mathrm{ppm}$ (averaged from the year 2070 until 2119) than in the control run (Fig. 2). Global annual mean temperature and precipitation increase by $4.4 \mathrm{~K}$ and $0.18 \mathrm{~mm} \mathrm{day}^{-1}(\sim 6.6 \%)$, respectively.

Global mean desert area, including deserts and glaciers, shrinks from $27 \%$ in 1850 to $23 \%$ in 2119 (averaged from 2090 to 2119), while trees and grass benefit from changed climate conditions and increased atmospheric $\mathrm{CO}_{2}$ concentration (Fig. 3). On a regional scale, vegetation cover expands and desert area shrinks in nearly all regions (Fig. 4). In the desert regions of the Sahara and Central Asia, the tree and the shrub cover increase. In the northern high latitudes, tree 

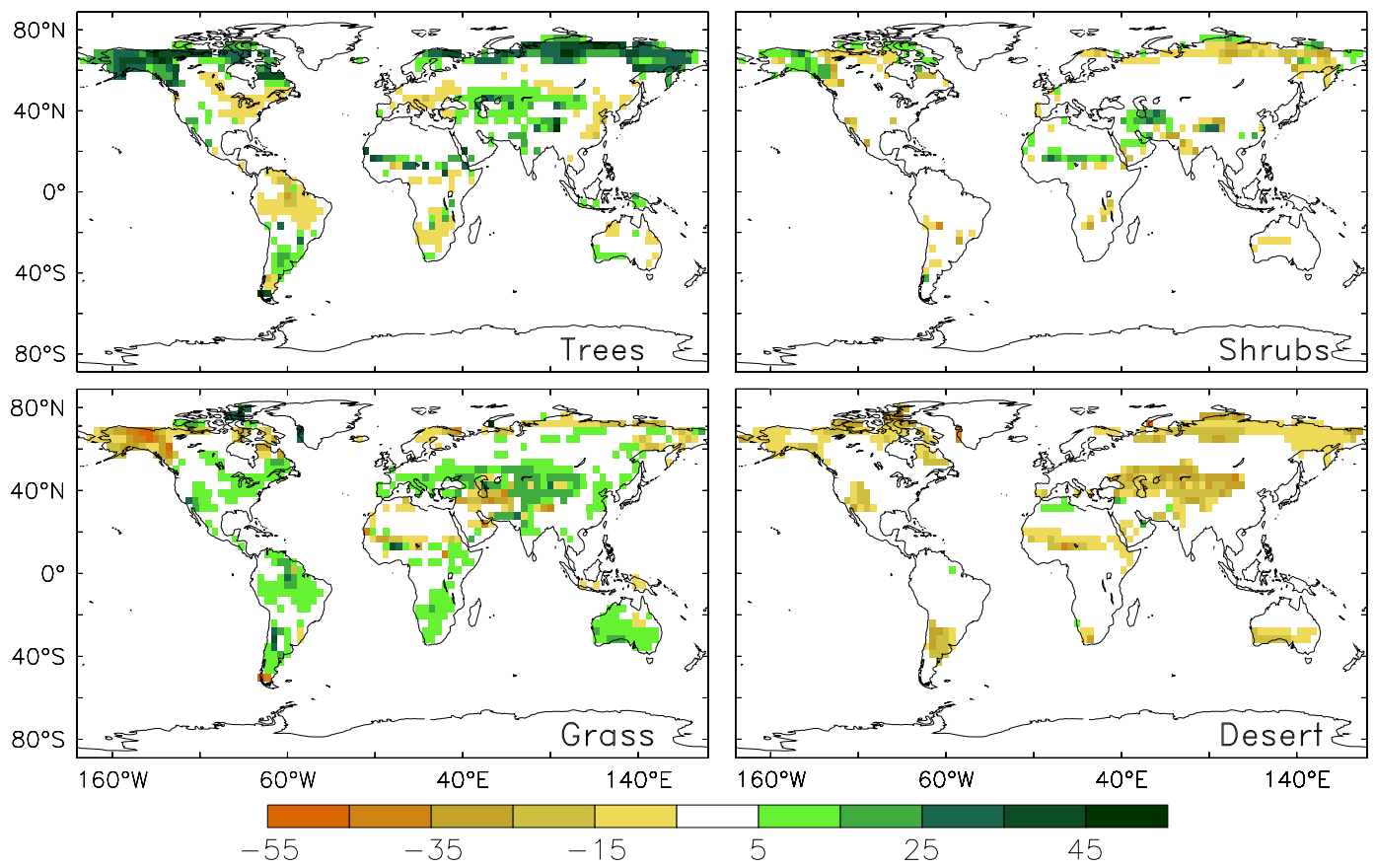

Fig. 4. Differences in absolute vegetation cover between the DYN and the CTL simulation averaged over the period from the year 2090 until 2119 given in $[\%]$.

cover extends. Trees succeed grass in Alaska, while they substitute shrubs in Siberia. Climate change results in declining tree cover in the Amazon region, where tree cover shrinks from $73 \%$ absolute coverage to $60 \%$ until the year 2120 . The trees are replaced by grass, which extends by the same amount of $13 \%$ area coverage.

In the period from 1850 until $2120, \mathrm{CO}_{2}$ fertilisation and changed climate conditions act on the terrestrial biosphere simultaneously. Changes in Net Primary Production (NPP) between the DYN and the control simulation reflect the influence of the $\mathrm{CO}_{2}$ fertilisation on photosynthesis rate and biomass build up. NPP increases nearly all over the globe by the year 2120 (Fig. 6). In contrast, NPP declines in parts of the Amazon region. Other than in the mid and high latitudes, where plant growth is dominated by temperature, water availability limits plant growth in the tropics and subtropics. A warming by $6.6 \mathrm{~K}$ in the Amazon region causes water stress and thus overcompensates $\mathrm{CO}_{2}$ fertilisation resulting in the tree cover decline by $13 \%$ absolute coverage.

The sensitivity of the Amazon forest to drying and the decline in the Amazonian tree cover due to anthropogenic climate change is known from previous studies (Betts et al., 2004; Notaro et al., 2007; Good et al., 2011). However, the magnitude of forest cover decline differs. Using the IS92a $\mathrm{CO}_{2}$ emission scenario, Betts et al. (2004) simulate a decline in precipitation of $60 \%$, causing a forest dieback from $80 \%$ to $10 \%$ absolute coverage during the 21 th century. In our simulations, precipitation change is smaller compared to Betts et al. (2004) resulting in a weaker forest cover decline.
NPP remains constant in desert regions, where water is rare and limits plant growth. However, NPP increases at the border of the deserts in the Sahara, the Middle East, Australia, and subtropical South America. As water stress is weaker in these regions than in the central desert areas, increased water-use efficiency becomes effective and NPP rises.

In short, $\mathrm{CO}_{2}$ fertilisation causes an increased NPP and leads to extended tree and grass cover in all regions, where climate conditions are favourable (northern high latitudes, Central Asia, and the borders of the large deserts). However, $\mathrm{CO}_{2}$ fertilisation becomes non-effective in regions of stronger water stress due to elevated temperatures and reduced precipitation (in parts of the Amazon region and central desert regions).

These findings are in line with previous studies. Bala et al. (2006) find a global mean increase in tree cover and a decline in grass- and shrubland cover due to $\mathrm{CO}_{2}$ fertilisation assuming the SRES A2 $\mathrm{CO}_{2}$ emission scenario. The continental deserts are replaced by trees and boreal forests extend northward in their simulations. In sensitivity studies on the physiological effect of elevated atmospheric $\mathrm{CO}_{2}$ on global vegetation cover by Bala et al. (2006), Notaro et al. (2007), and O'ishi and Abe-Ouchi (2009), the strongest influence of $\mathrm{CO}_{2}$ fertilisation on vegetation has been found in moisturelimited regions, where increased water-use efficiency leads to extended plant growth. 


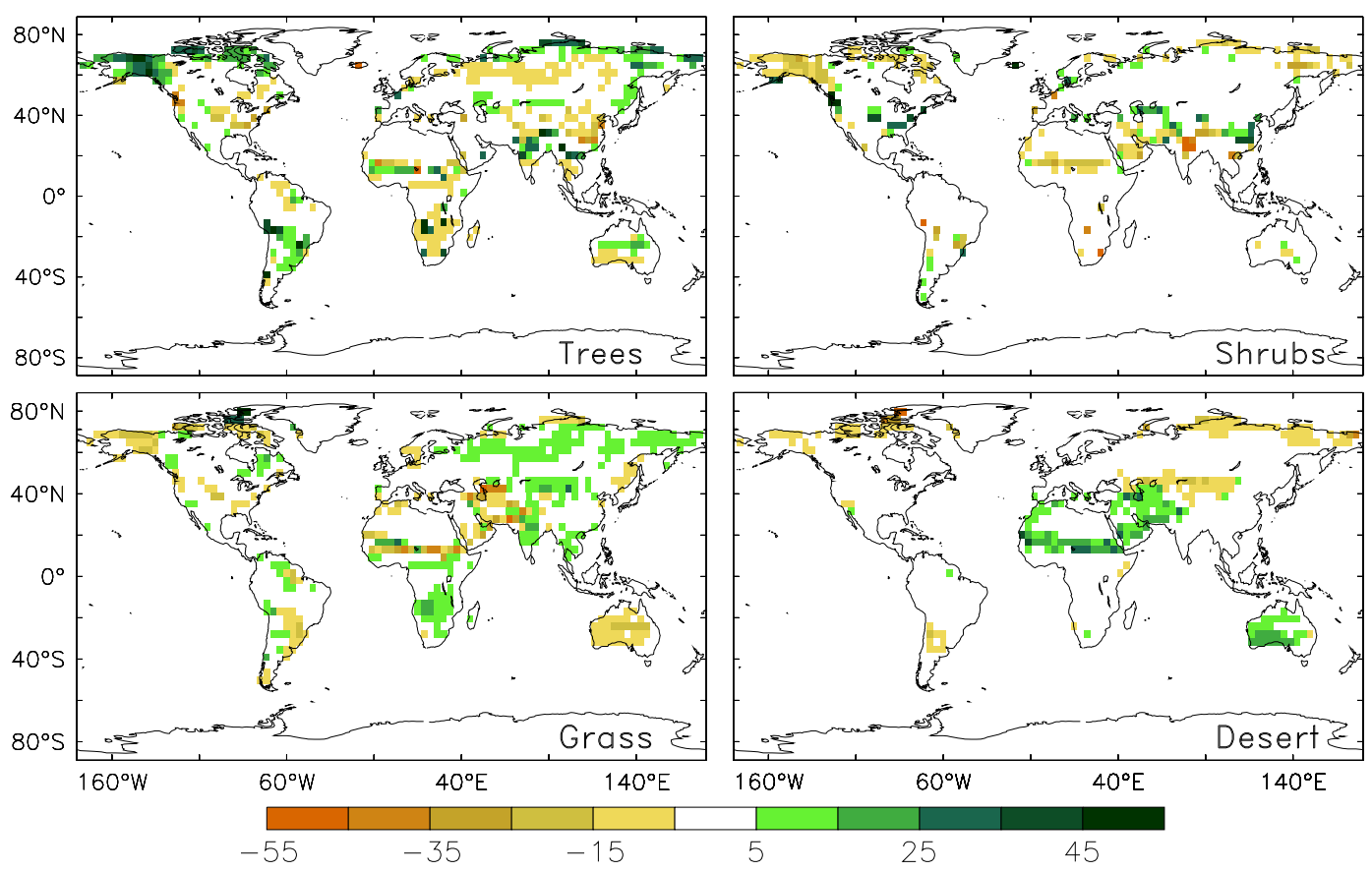

Fig. 5. Changes in absolute vegetation cover in [\%] from 2120 (averaged over the period from the year 2090 until 2119 ) until 2300 (averaged over the period from the year 2270 until 2299).

Besides the $\mathrm{CO}_{2}$ fertilisation effect, extended growing periods facilitate boreal forests to expand in the northern high latitudes by the year 2120. Mean temperature over land increases by $8.3 \mathrm{~K}$ in the northern high latitudes averaged from 2090 until 2119 (DYN - CTL). Especially winters become warmer, as the mean temperature in January increases by $15 \mathrm{~K}$ over land. The warming in spring and autumn shortens the period with snow covering the ground. Hence, vegetation growth becomes more suitable during this time and the growth season extends. Furthermore, precipitation increases by $29 \%$ (DYN - CTL), leading to a larger amount of water available for plant growth.

The vegetation cover in the Sahara responds to $\mathrm{CO}_{2}$ fertilisation, but also depends on precipitation. Figure 7 illustrates the time series for changes in vegetation cover and in annual mean precipitation in the Sahara. Precipitation over land averaged from the year 2060 until 2089 increases by $20 \%$ related to the control simulation (DYN - CTL). In combination with the $\mathrm{CO}_{2}$ fertilisation, the higher precipitation rate leads to an increase in tree and shrub cover from $7 \%$ to $10 \%$ and $3 \%$ to $5 \%$, respectively, until 2089 (averaged from 2060 until 2089). The desert area shrinks from $77 \%$ to $72 \%$ absolute coverage. The grass cover extension stays constant since predominantly $\mathrm{C}_{4}$ grass occurs. In JSBACH, $\mathrm{C}_{4}$ grass does not response to increased atmospheric $\mathrm{CO}_{2}$ concentration, i.e. no $\mathrm{CO}_{2}$ fertilisation effect on $\mathrm{C}_{4}$ grass occurs. From 2090 on, precipitation declines and temperature continues to increase. The desert area increases instantaneously due to the resulting water stress. Thereby, shrub and grass cover decline, while tree cover still increases. The competition between the plant types in JSBACH is based on the NPP of the plants. While the NPP of trees increases, the NPP of grass and shrubs decline. These changes in NPP lead to the vegetation shift from grassland to a woody savanna in the Sahara.

\subsection{Changes in climate and vegetation cover during climate stabilisation (2120-2300)}

At the end of the simulation, the atmospheric $\mathrm{CO}_{2}$ concentration is $497 \mathrm{ppm}$ above the pre-industrial value (Fig. 2). The global annual mean temperature and precipitation continue to increase until about the year 2150. From 2200 until 2300, the global annual mean temperature reveals no significant trend, while global annual mean precipitation declines slightly $\left(0.0014 \mathrm{~mm} \mathrm{day}^{-1}\right.$ in $\left.100 \mathrm{yr}\right)$. The global mean temperature and precipitation in DYN are $5.6 \mathrm{~K}$ and $0.3 \mathrm{~mm}^{-1 a y}{ }^{-1}(\sim$ $10 \%$ ) higher than in the control run by 2300 .

The global mean desert area increases slightly and shrub as well as grass cover shrink from 2120 until 2200 (Fig. 3). In contrast, the global mean tree cover continues to expand. From 2200 onwards, the global mean vegetation cover tends to stabilise.

Figure 3 further illustrates the response time of vegetation to anthropogenic climate change. The $\mathrm{CO}_{2}$ emissions are switched off in the year 2120, the temperature increases until about 2170 (Fig. 2), and the vegetation cover changes strongly until about 2220 . In other words, even $100 \mathrm{yr}$ after the shut down of the emissions, the terrestrial biosphere 


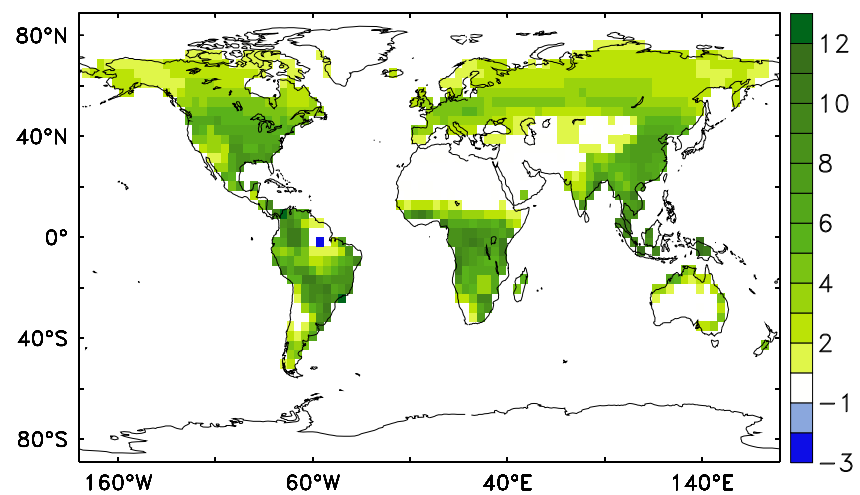

Fig. 6. Differences in Net Primary Productivity (NPP) caused by anthropogenic $\mathrm{CO}_{2}$ emissions and vegetation dynamics in $\left[\mathrm{mol}(\mathrm{C}) / \mathrm{m}^{2} \mathrm{yr}\right](\mathrm{DYN}-\mathrm{CTL})$ averaged over the period from the year 2090 until 2119.

changes due to the $\mathrm{CO}_{2}$ emissions. This long response time let us conclude that even if humankind shut down the emissions today, the vegetation cover would change significantly.

In the period from 2120 to 2300 , the tree cover further extends northward at the expense of the tundra (Fig. 5). The tree cover increase is strongest in Alaska, where trees replace shrubs and grass. In contrast, tree cover shrinks in the taiga region since precipitation declines. This northward shift of the boreal forest has also been found by Notaro et al. (2007) and O'ishi and Abe-Ouchi (2009).

In response to intensified precipitation rates in southern South America even after 2120, tree cover proceeds to increase in this region. Thus, a bipolar pattern occurs in South America by 2300 , with reduced tree cover in the north and extended tree cover in the south.

Compared to the period from 1850 until $2120, \mathrm{CO}_{2}$ fertilisation weakens after $\mathrm{CO}_{2}$ emissions cease. Thus, climate change and weakening $\mathrm{CO}_{2}$ fertilisation affect the terrestrial biosphere after the year 2120. Especially the vegetation in the desert regions responds to the weakening of the $\mathrm{CO}_{2}$ fertilisation. In the desert regions of Australia and Arabia, the decline in atmospheric $\mathrm{CO}_{2}$ and the further climate change cause desert area expansion compared to 2120. In the Sahara, stronger water stress, initiated by decreased precipitation, adds to the weaker $\mathrm{CO}_{2}$ fertilisation (Fig. 7). The decline in precipitation rate which is visible around 2100 continues leading to a $35 \%$ smaller precipitation rate in the DYN simulation than in the control run by 2300 . The desert area extends from $77 \%$ in the pre-industrial state to $82 \%$ by 2300 . Grass and shrubs are unable to survive, while tree cover still persists. The reason for this vegetation shift is again the change in NPP. For trees, NPP increases, while the NPP of grass and shrubs decline.

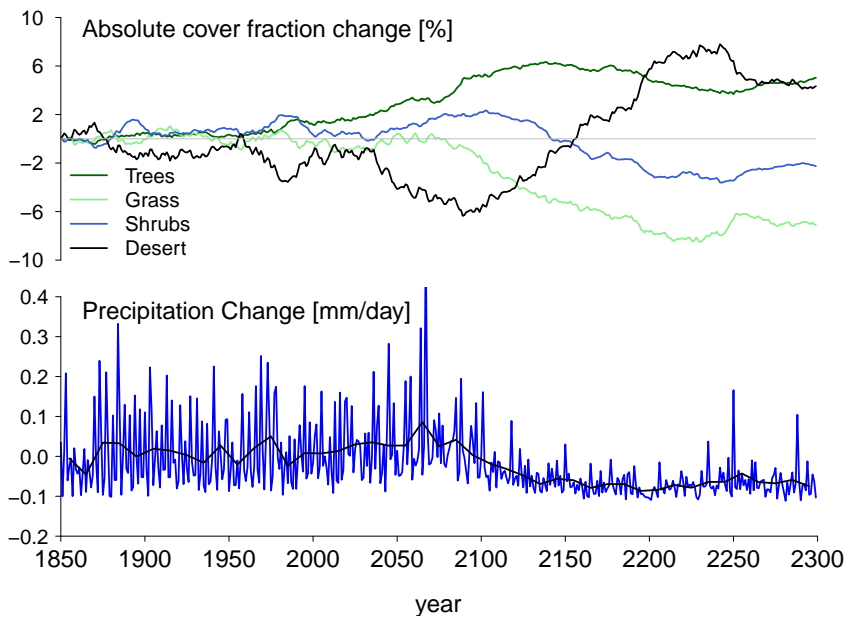

Fig. 7. Time series of differences in vegetation cover (top figure) in the Sahara/Sahel region $\left(20^{\circ} \mathrm{W}-45^{\circ} \mathrm{E}\right.$ and $\left.10^{\circ} \mathrm{N}-35^{\circ} \mathrm{N}\right)$. The bottom figure shows the differences in annual mean precipitation over land (blue) and the differences in $10 \mathrm{yr}$ mean precipitation over land (black) due to anthropogenic climate change and vegetation cover change (DYN - CTL).

\subsection{Impact of dynamic vegetation on climate around 2300}

The impact of vegetation dynamics on climate can be assessed by comparing the DYN and the STAT simulation. Thereby, we find that natural vegetation cover shifts lead to a lower atmospheric $\mathrm{CO}_{2}$ concentration by $37 \mathrm{ppm}$ and a lower global mean temperature by $0.22 \mathrm{~K}$ averaged over the years from 2270 until 2299 (Fig. 2). On a regional scale, a cooling due to vegetation dynamics occurs in South America, Alaska, northern Africa, and parts of Asia (DYN - STAT) as shown in Fig. 8a. The impact on the annual mean precipitation on a regional and a global scale is negligibly small and thus not depicted here.

\subsubsection{Biogeophysical effect of vegetation dynamics on climate}

In order to separate the biogeophysical effect from the net effect of vegetation dynamics on climate, the differences between the DYN and the STAT_PS simulations are analysed in this subsection.

The biogeophysical effect of vegetation cover changes has no significant effect on global annual mean temperature, but influences regional climate (Fig. 8 b). The biogeophysical effect leads to a warming in Eastern Europe, Siberia, around the Hudson Bay, and in the Amazon region. In southern South America, the biogeophysical effect of vegetation dynamics is a cooling.

In the northern high latitudes, the biogeophysical effect of the northward expanded tree cover affects two components of the energy budget. Expanded boreal forests leads to a lower 

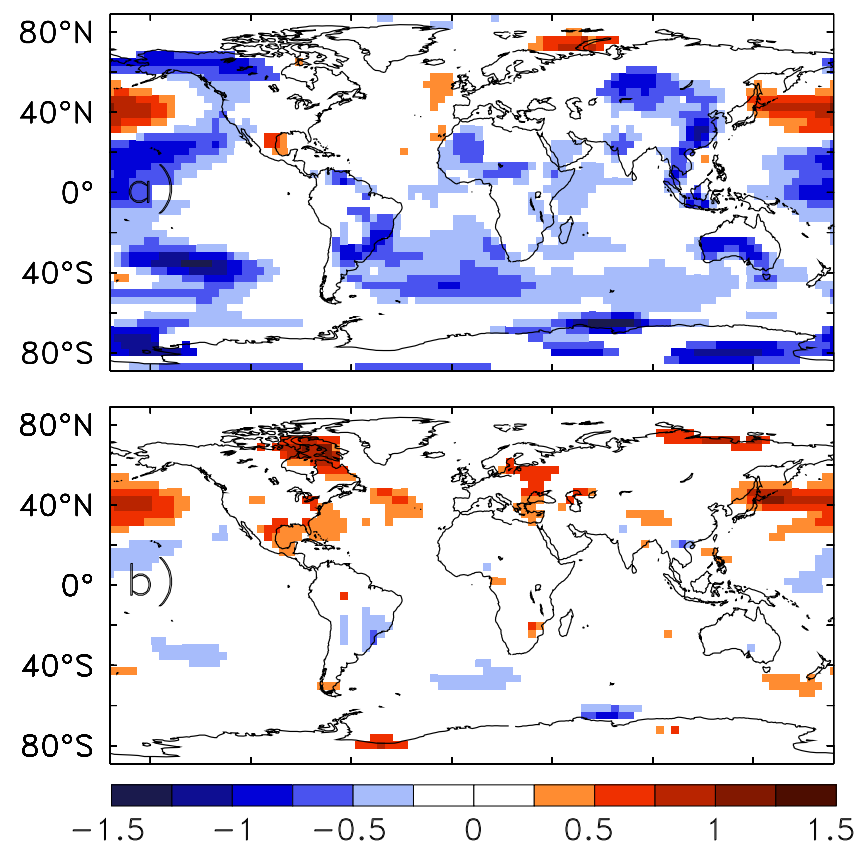

Fig. 8. Differences in annual mean temperature due to the net effect of vegetation dynamics (DYN - STAT) in (a) and caused by the biogeophysical (DYN - STAT_PS) in (b). The differences are averaged over the period from the year 2270 until 2299. Shown differences are significant on a $95 \%$ level of significance.

regional land surface albedo and thus a higher net shortwave radiation in the DYN than in the STAT_PS simulation. The resulting regional warming over land depends strongly on the season (Fig. 9). In late winter and early spring, a strong albedo reduction occurs. The dominant effect causing this decline is the snow-masking effect of trees. Even for deciduous trees, dark trunks, branches, and twigs mask the snow and thus lead to a lower albedo (Bergengren et al., 2001; Bonan, 2008). The snow-masking effect is strong in spring, when snow still covers the ground and insolation increases. The snow-masking effect leads to the higher April temperatures over land in the DYN than in the STAT_PS simulation.

Expanded tree cover further affects the climate in the high latitudes by leading to an increased evapotranspiration rate. The higher evapotranspiration rate in the DYN than in the STAT_PS simulation causes a cooling since the latent heat flux is higher. The maximum evapotranspiration differences between the DYN and the STAT_PS simulation occurs in summer (Fig. 9) as trees carry a maximum amount of leaves in this time. During this season, the warming impact of the albedo reduction weakens and the influence of increased evapotranspiration becomes more dominant. In the temperature difference between the DYN and STAT PS simulation, the strengthening of the impact of the evapotranspiration differences is evident in the weaker warming in July and August.

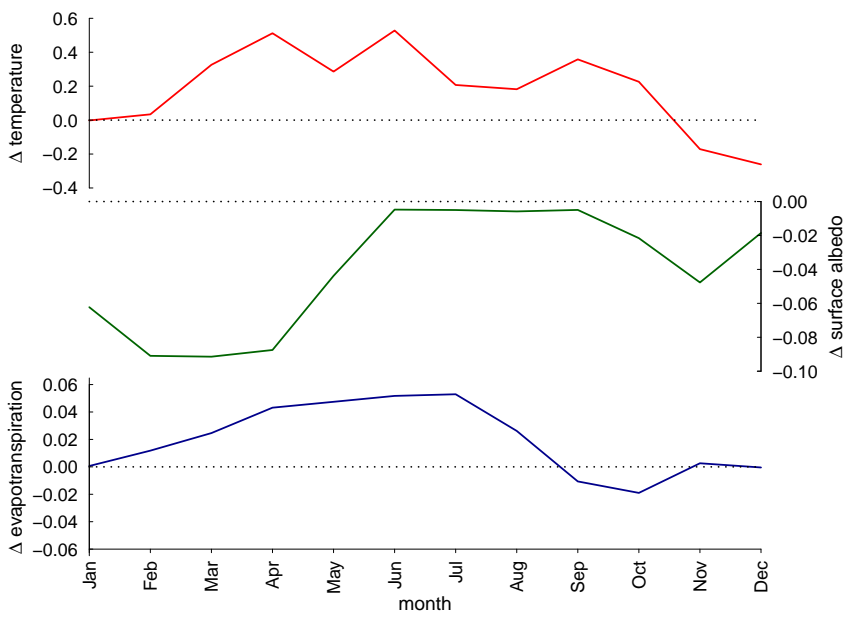

Fig. 9. Differences in the annual cycle of monthly mean temperature in [K] (red line), surface albedo [/] (green line), and evapotranspiration in $\left[\mathrm{mm} \mathrm{day}^{-1}\right]$ (blue line) in the northern high latitudes $\left(60^{\circ} \mathrm{N}\right.$ to $80^{\circ} \mathrm{N}$, only land) caused by the biogeophysical effect of vegetation dynamics (DYN - STAT_PS) averaged over the period from the year 2070 until 2299.

In the annual mean, the effect of reduced land surface albedo in spring outweighs the effect of increased latent heat flux in summer. Thus, the biogeophysical effect of extended tree growth in the northern high latitudes is a warming over land of $0.13 \mathrm{~K}$ (DYN - STAT_PS). These results agree with Levis et al. (1999), who find the same counteracting effects of higher evapotranspiration rates and lower surface albedo due to tree cover expansion in the northern high latitudes.

The biogeophysical effect of vegetation cover shifts on climate in the Amazon region is a slight warming by $0.07 \mathrm{~K}$ and a decrease in precipitation by $2.8 \%$. Compared to the STAT_PS simulation, tree cover is smaller in the DYN simulation leading to less evapotranspiration, initiating two counteracting effects. Lower evapotranspiration rates cause a warming since sensible heat fluxes are higher and latent heat fluxes are lower. Furthermore, weaker evapotranspiration leads to a cooling as specific humidity is smaller and thus the loss of thermal radiation is larger. However, the cooling due to the smaller specific humidity is weaker than the warming due to the decrease in latent heat flux. In sum, the biogeophysical effect causes a warmer and dryer Amazon region. Cox et al. (2004) suggest that a forest dieback results in a stronger reduction of precipitation rates than we find and leaves temperature unaffected. The decline in tree cover suggested by Cox et al. (2004) is stronger than in our results. Therefore, a weaker response in precipitation is plausible. Why the results concerning temperature changes differ remains unclear.

No statistically significant biogeophysical effect on the mean climate due to vegetation dynamics occurs in the Sahara. However, vegetation changes influence the variability in precipitation. The mean climate in the Sahara region 


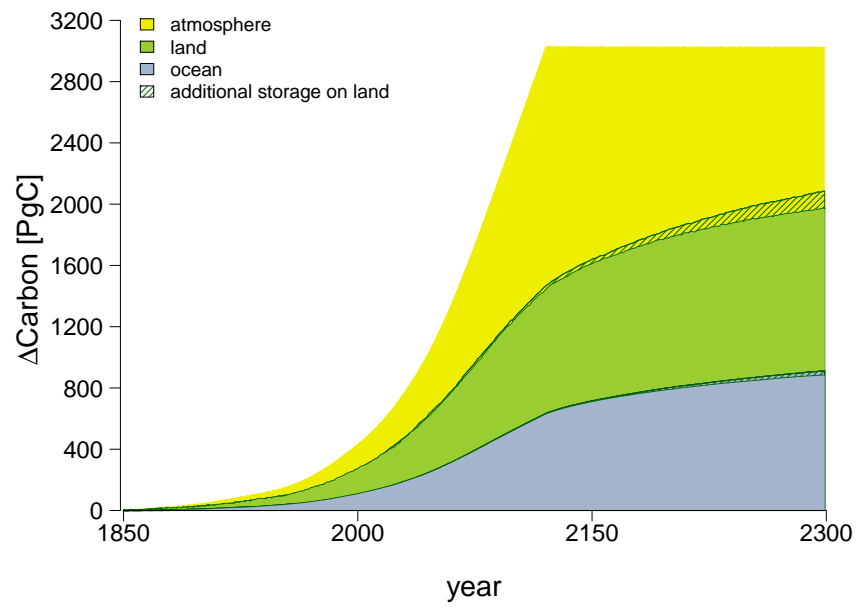

Fig. 10. Cumulated carbon budget simulated with the static preindustrial vegetation cover. The shaded areas reflect the additional carbon storage on land due to vegetation cover changes. This additional land carbon storage leads to reduced carbon in the ocean (dark green shade over grey area) and in the atmosphere (dark green shade over yellow area).

becomes drier and also the variability in precipitation declines due to anthropogenic climate change, as visible in the differences in the standard deviation between the DYN $\left(0.036 \mathrm{~mm} \mathrm{day}^{-1}\right)$ and the CTL $\left(0.072 \mathrm{~mm} \mathrm{day}^{-1}\right)$ simulation. These values are calculated based on the last $100 \mathrm{yr}$ of each simulation. The standard deviation in the STAT and STAT_PS simulations are even lower than in the DYN simulation with both $0.026 \mathrm{~mm} \mathrm{day}^{-1}$. These lower standard deviations indicate that vegetation changes attenuate the reduction in precipitation variability. We define a high precipitation year as a year with $20 \%$ more precipitation than the mean over the last $100 \mathrm{yr}$ of the simulation. In the control run and in the DYN simulation, high precipitation years occur 28 and 19 times in the last $100 \mathrm{yr}$, respectively. In the STAT and STAT_PS, 13 and 17 high precipitation years occur, respectively. The higher variability in precipitation in the DYN simulation coexists with a higher soil moisture by $3.1 \%$ than in the STAT_PS simulation. The evapotranspiration in the DYN simulation is lower than in the STAT_PS simulation in the Sahara. Hence, the higher soil moisture is rather the result than the reason for the higher variability in precipitation. In summary, our simulations suggest that vegetation changes attenuate the reduction in precipitation variability and lead to a higher soil moisture. Thus, vegetation dynamics counteract the drying due to anthropogenic climate change in the Sahara.

\subsubsection{Biogeochemical effect of vegetation dynamics on climate}

Comparing the carbon storage on the land, in the ocean, and in the atmosphere in the DYN and in the STAT simulation

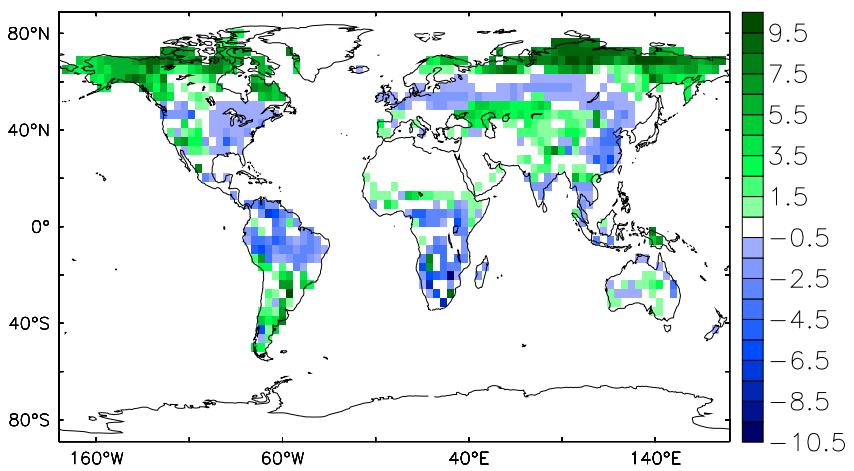

Fig. 11. Differences in total land carbon storage (sum of the biomass, soil, and litter pool) due to changes in vegetation cover in $\left[\mathrm{kgC} \mathrm{m}^{2}\right]$ (DYN - STAT) averaged over the period from the year 2270 until 2300.

illustrates the impact of vegetation dynamics on the carbon cycle. Until the year 2120, the impact of vegetation cover shifts on the carbon cycle is weak (Fig. 10) since only small differences in land, ocean, and atmosphere carbon storage between the DYN and the STAT simulation occur. However, vegetation dynamics clearly influence the global carbon budget after the emissions cease. After 2120, the land and the ocean take up carbon from the atmosphere in both simulation, DYN, and STAT. Though, in the DYN simulation the land carbon uptake is higher than in the STAT simulation. Land stores $39 \%$ of the anthropogenic $\mathrm{CO}_{2}$ emissions in the DYN simulation by 2300 , while the land stores $35 \%$ in the STAT simulation. Thus, less carbon remains in the atmosphere in the DYN than in the STAT simulation and the radiative forcing is weaker.

The difference in the land carbon uptake between the DYN and the STAT simulation does not become visible until 2120, since the largest difference occurs in the soil carbon uptake. The land carbon storage is subdivided into three components: the vegetation, the litter, and the soil carbon pool. The response time of the soil carbon pool is long since the processes which transfer carbon from the litter and vegetation pool to the soil pool act on long-term scales.

Changes in the geographical distribution of carbon storage due to vegetation dynamics are consistent with tree cover changes (Fig. 11). In agreement with Jones et al. (2010), a larger boreal forest extension in the DYN simulation than in the STAT simulation leads to an additional terrestrial carbon storage in the northern high latitudes. In comparison to the STAT simulation, the carbon storage is higher in the south and lower in the north of South America, as the tropical trees shift southward in the DYN simulation. In the continental interior arid regions, the carbon storage is equal in both simulations. Since tree cover in the Sahel zone spreads, regional carbon storage is slightly larger in the DYN than in the STAT simulation in this region. On a global scale, the extended global mean tree cover leads to a higher total land carbon 
storage by $11 \%$ when comparing the DYN and the STAT simulation.

The additional land carbon uptake due to vegetation dynamics leads to a $37 \mathrm{ppm}$ lower atmospheric $\mathrm{CO}_{2}$ concentration in the DYN simulation compared to the STAT simulation (Fig. 2). This biogeochemical effect results in a cooler global climate. In general, we could quantify the biogeochemical effect by subtracting the biogeophysical effect (DYN STAT_PS) from the net effect of vegetation dynamics (DYN - STAT). However, the biogeophysical effect has no significant impact on global mean temperature. Therefore, we forbear from quantifying the magnitude of the biogeochemical effect based on our simulations.

\section{Conclusions}

In this study, the interaction between the natural vegetation cover and the anthropogenically induced climate change on the centennial time scale is assessed using the MPI ESM, which includes an interactive carbon cycle and dynamic vegetation. The model is forced by a $\mathrm{CO}_{2}$ emission scenario that combines the RCP 8.5 scenario until the year 2120 and zero emissions from 2120 until 2300.

The interactive vegetation significantly responds to fossil fuel emissions and climate change. Firstly, trees in the northern high latitudes benefit from the prolonged growing season and extend northward into the tundra region. In contrast, at the southern border of the taiga region, warming and resultant increased water stress cause the tree cover to decline by 2300. Secondly, the vegetation cover increases in the subtropical desert areas due to $\mathrm{CO}_{2}$ fertilisation and enhanced water-use efficiency until 2120. After the emissions cease, the atmospheric $\mathrm{CO}_{2}$ concentration declines. Subsequently, desert area extends again since $\mathrm{CO}_{2}$ fertilisation becomes weaker in comparison to the year 2120. In the Sahara, decreased precipitation suppresses greening even before 2120 . Until the year 2090, precipitation increases in the Sahara region, but afterwards it declines. The resulting drying leads to an expansion of the desert area. Thirdly, a $13 \%$ decline in tree cover is found in the Amazon region, which is a substantial forest dieback but not as strong as suggested by Betts et al. (2004).

The shifts in vegetation cover have no significant biogeophysical impact on global climate. However, the biogeophysical effect is substantial on a regional scale. In the northern high latitudes, the snow masking effect of the shifting tree cover leads to an additional warming. In the Amazon region, decreased tree cover leads to a reduced evapotranspiration causing a regional warming due to decreased latent heat fluxes.

In the Sahel region, the vegetation cover evolves towards savannah with more trees and less grasses than in the initial state. This shift does not affect the mean climate. However, the variability in precipitation remains higher in the simu- lation with dynamic vegetation compared to the simulation with the static pre-industrial vegetation cover. Further, the vegetation shift favours the concurrence of high precipitation events.

Extended global mean vegetation cover results in an increased land carbon storage by $11 \%$. The enhanced land carbon storage leads to a lower atmospheric $\mathrm{CO}_{2}$ concentration by $37 \mathrm{ppm}$ in 2300. Hence, the biogeochemical effect of vegetation dynamics is a global cooling. However, the impact of vegetation dynamics on the carbon cycle is not visible until 2120. By 2300, especially the soil carbon storage becomes larger when considering vegetation dynamics. Since the response of the soil carbon pool is slow, the biogeochemical effect of vegetation dynamics becomes visible at centennial time scale.

The net effect of natural vegetation cover changes (biogeophysical plus biogeochemical) on the global climate is a cooling by $0.22 \mathrm{~K}$ by 2300 . Since the impact of the biogeophysical effect on the global climate is not significant, the biogeochemical effect is the dominant effect on the centennial time scale. In other words, the increased land carbon uptake due to the extended global mean tree cover leads to a cooler climate and attenuates anthropogenic climate change. Again, we would like to emphasise that land use change is neglected in our study. Thus, the result of a cooling effect due to increased land carbon uptake should be considered as a notional result. Land use change, and especially deforestation, are suggested to lead to carbon release, which likely counteract or even offset the additional land carbon uptake due to natural vegetation dynamics.

The response time of the vegetation cover to anthropogenic $\mathrm{CO}_{2}$ emissions and climate change in our simulations is about $100 \mathrm{yr}$. From this response time, we conclude that vegetation shifts initiated by the $\mathrm{CO}_{2}$ emissions until today are likely to take place even if humankind shut down the emissions immediately. This stresses the importance of the concept of committed climate and vegetation changes expressed by Jones et al. (2009).

Acknowledgements. We would like to thank Veronika Gayler for the technical support and Thomas Raddatz for useful comments on the manuscript. We are also grateful to Chris Jones and an anonymous reviewer for their constructive comments.

The service charges for this open access publication have been covered by the Max Planck Society.

Edited by: G. Bala

\section{References}

Bala, G., Caldeira, K., Mirin, A., Wickett, M., Delire, C., and Phillips, T. J.: Biogeophysical effects of $\mathrm{CO}_{2}$ fertilization on global climate, Tellus B, 58, 620-627, 2006. 
Bala, G., Caldeira, K., Wickett, M., Phillips, T. J., and Lobell, D. B.: Combined climate and carbon-cycle effects of large-scale deforestation, Proc. Natl. Acade. Sci. USA, 104, 6550-6555, 2007.

Bathiany, S., Claussen, M., Brovkin, V., Raddatz, T., and Gayler, V.: Combined biogeophysical and biogeochemical effects of largescale forest cover changes in the MPI earth system model, Biogeosciences, 7, 1383-1399, doi:10.5194/bg-7-1383-2010, 2010.

Beck, P. S. A. and Goetz, S.: Satellite observations of high northern latitude vegetation productivity changes between 1982 and 2008: ecological variability and regional differences, Environ. Res. Lett., 6, 045501, doi:10.1088/1748-9326/6/4/045501, 2011.

Bergengren, J. C., Thompson, S. L., Pollard, D., and DeConto, R. M.: Modeling global climate-vegetation interactions in a doubled $\mathrm{CO}_{2}$ world, Climatic Change, 50, 31-75, 2001.

Betts, R. A., Cox, P. M., Collins, M., Harris, P. P., Huntingford, C., and Jones, C. D.: The role of ecosystem-atmosphere interactions in simulated Amazonian precipitation decrease and forest dieback under global climate warming, Theor. Appl. Climatol., 78, 157-175, 2004.

Bonan, G. B.: Forests and Climate Change: Forcings, Feedbacks, and the Climate Benefits of Forests, Science, 320, 1444-1449, 2008.

Brovkin, V.: Climate-vegetation interaction, J. Phys. IV, 12, 57-72, 2002.

Brovkin, V., Raddatz, T., and Reick, C. H.: Global biogeophysical interactions between forest and climate, Geophys. Res. Lett., 36, L07405, doi:10.1029/2009GL037543, 2009.

Claussen, M., Brovkin, V., and Ganopolski, A.: Biogeophysical versus biogeochemical feedbacks of large-scale land cover change, Geophys. Res. Lett., 28, 1011-1014, 2001.

Cox, P. M., Betts, R. A., Collins, M., Harris, P. P., Huntingford, C., and Jones, C. D.: Amazonian forest dieback under climatecarbon cycle projections for the 21st century, Theor. Appl. Climatol., 78, 137-156, 2004.

de Boera, H. J., Lammertsmab, E. I., Wagner-Cremerb, F., Dilcherc, D. L., Wassena, M. J., and Dekkera, S. C.: Climate forcing due to optimization of maximal leaf conductance in subtropical vegetation under rising $\mathrm{CO}_{2}$, Proc. Natl. Acad. Sci., 108, 4041-4046, 2011.

Essery, R., Rutter, N., Pomeroy, J., Baxter, R., and Stahli, M.: An Evaluation of Forest Snow Process Simulations, B. Am. Meteorol. Soc., 90, 1120, doi:10.1175/2009BAMS2629.1, 2009.

Good, P., Jones, C., Lowe, J., Betts, R., and Booth, B.: Quantifying Environmental Drivers of Future Tropical Forest Extent, J. Climate, 24, 1337-1349, 2011.

Jones, C., Lowe, J., Liddicoat, S., and Betts, R.: Committed terrestrial ecosystem changes due to climate change, Nat. Geosci., 2, 484-487, doi:10.1038/ngeo555, 2009.

Jones, C., Liddicoat, S., and Lowe, J.: Role of terrestrial ecosystems in determining $\mathrm{CO}_{2}$ stabilization and recovery behaviour, Tellus B, 62, 682-699, 2010.

Jungclaus, J. H., Keenlyside, N., Botzet, M., Haak, H., Luo, J. J., Latif, M., Marotzke, J., Mikolajewicz, U., and Roeckner, E.: Ocean circulation and tropical variability in the coupled model ECHAM5/MPI-OM, J. Climate, 19, 3952-3972, 2006.

Levis, S., Foley, J. A., and Pollard, D.: $\mathrm{CO}_{2}$, climate, and vegetation feedbacks at the Last Glacial Maximum, J. Geophys. Res.Atmos., 104, 31191-31198, 1999.
Matthews, H. D., Weaver, A. J., Meissner, K. J., Gillett, N. P., and Eby, M.: Natural and anthropogenic climate change: incorporating historical land cover change, vegetation dynamics and the global carbon cycle, Clim. Dynam., 22, 461-479, doi:10.1007/s00382-004-0392-2, 2004.

Meehl, G. A., Stocker, T. F., Collins, W. D., Friedlingstein, P., Gaye, A. T., Gregory, J. M., Kitoh, A., Knutti, R., Murphy, J. M., Noad, A., Raper, S. C. B., Watterson, I. G., Weaver, A. J., and Zhao, Z.C.: Global Climate Projections, in: Climate Change 2007: The physical science basis. Contribution of Working Group I to the Fourth Assessment Report of the Intergovernmental Panel on Climate Change, Cambridge University Press, 747-845, 2007.

Menzel, A. and Fabian, P.: Growing season extended in Europe, Nature, 397, 659-659, 1999.

Myneni, R. B., Keeling, C. D., Tucker, C. J., Asrar, G., and Nemani, R. R.: Increased plant growth in the northern high latitudes from 1981 to 1991, Nature, 386, 698-702, 1997.

Notaro, M., Vavrus, S., and Liu, Z.: Global vegetation and climate change due to future increases in $\mathrm{CO}_{2}$ as projected by a fully coupled model with dynamic vegetation, J. Climate, 20, 70-90, 2007.

O'ishi, R. and Abe-Ouchi, A.: Influence of dynamic vegetation on climate change arising from increasing $\mathrm{CO}_{2}$, Clim. Dynam., 33, 645-663, 2009.

Piao, S., Wang, X., Ciais, P., Zhu, B., and Wang, T.: Changes in satellite-derived vegetation growth trend in temperate and boreal Eurasia from 1982 to 2006, Global Change Biol., 17, 3228-3239, 2011.

Raddatz, T. J., Reick, C. H., Knorr, W., Kattge, J., Roeckner, E., Schnur, R., Schnitzler, K.-G., Wetzel, P., and Jungclaus, J.: Will the tropical land biosphere dominate the climate-carbon cycle feedback during the twenty-first century?, Clim. Dynam., 29, 565-574, 2007.

Roeckner, E., Brokopf, R., Esch, M., Giorgette, M., Hagemann, S., Kornblueh, L., Manzini, E., Schlese, U., and Schulzweida, U.: The general circulation model ECHAM5. Part I: Model description. Report 349, Max-Planck-Institut for Meteorology, Hamburg, 2003.

Snyder, P. K., Delire, C., and Foley, J. A.: Evaluating the influence of different vegetation biomes on the global climate, Clim. Dynam., 23, 279-302, 2004.

Wetzel, P., Winguth, A., and Maier-Reimer, E.: Sea-to-air $\mathrm{CO}_{2}$ flux from 1948 to 2003: A model study, Global Biogeochem. Cy., 19, GB2005, doi:10.1029/2004GB002339, 2005.

Woodward, F. I. and Beerling, D. J.: The dynamics of vegetation change: health warnings for equilibrium "dodo" models, Global Ecol. Biogeogr. Lett., 6, 413-418, 1997.

Yurova, A. Y. and Volodin, E. M.: Coupled simulation of climate and vegetation dynamics, Izvestiya, Atmos. Ocean. Phys., 47, 531-539, 2011.

Zhou, L. M., Tucker, C. J., Kaufmann, R. K., D., S., and Shabanov, N. V.: Variations in northern vegetation activity inferred from satellite data of vegetation index during 1981 to 1999 , J. Geophys. Res., 106, 20069-20083, 2001. 